\title{
Historical Perspectives of The American Association for Thoracic Surgery: Aldo Castañeda
}

\author{
Jennifer C. Romano, MD, MS, ${ }^{\mathrm{a}}$ and J. William Gaynor, $\mathrm{MD}^{\mathrm{b}}$
}

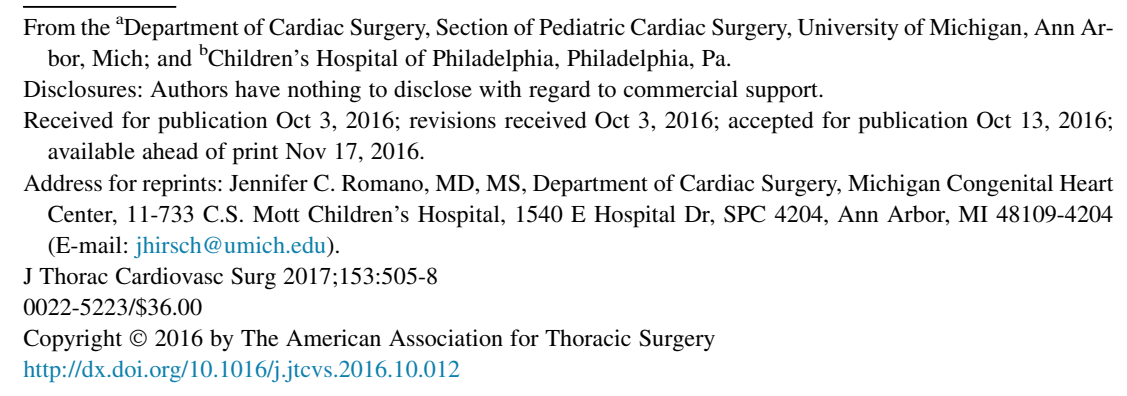

Our profession is built on the amazing intellect and technical skill of outstanding surgeons who have pushed the field to new heights and inspired others to do the same. Many receive accolades such as technically brilliant, innovative, and driven; but never has there been a leader in our profession who is also repeatedly noted as a "cherished" surgeon "held in great affection" by peers, trainees, and collaborators. ${ }^{1}$ Aldo Castañeda, MD, PhD (74th president of the American Association for Thoracic Surgery [AATS]), is unique in the emotions that are conjured when his name is mentioned. Upon first meeting, this tall, eloquent gentleman with a shock of white hair immediately garners attention and an audience (Figure 1). Those of us in the field of congenital heart surgery know that every surgeon in the profession has been in some way or another touched by his approach to patient care, education, and collaboration. As a teacher and mentor, he has directly trained more than 100 pediatric cardiac surgeons, 44 of whom have become heads of programs for pediatric cardiac surgery around the world.

Castañeda is a true Renaissance man with a multicultural background that shaped his persona and career. He was born in Genoa, Italy, in 1930 to Guatemalan parents. At age 5 years, his family moved to Munich, Germany, for his father's medical training. He was in third grade when World War II began. By 1941, because they were Guatemalan citizens, the Castañeda family was viewed as enemy foreigners and not allowed to leave Germany. Many of Castañeda's formative years were spent in Nazi Germany, which dramatically influenced his approach to life and education. His family was ultimately able to leave Germany in 1946. While at a meeting in Poland in 2008, Castañeda gave an address retelling the story of his life during World War II, including surviving in the basement of his family home while the structure above ground was destroyed by a bomb during an air raid when he was 14 years old. ${ }^{2}$ This story provides just a glimpse into the life experiences that created this complex man.

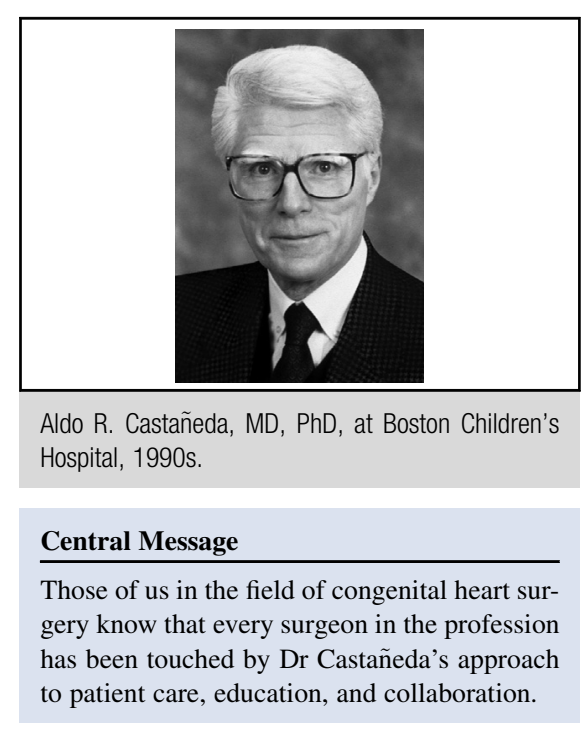

Castañeda returned to Europe to complete his college requirements at the Institut auf dem Rosenberg in St Gallen, Switzerland. With growing concerns for a possible third World War, he left Europe in 1951 for Guatemala to study medicine. He soon was named the best medical student every year following his first. In 1958, he received the Justo Rufino Barrios award as the best student at the University of Guatemala. His graduation thesis was entitled "Open Heart Surgery: An Experimental Study." It was based on his medical student research that was performed in 1956-1957. This area of research is quite notable when one realizes that the history of cardiac surgery had just begun in 1952 with the first open heart surgery at the University of Minnesota in the United States. His innovative laboratory research represented the first attempts at open heart surgery anywhere in Central America. More than a half a century later, Castaneda remains a leader in cardiac innovation in Central America with his ongoing contributions to the care of patients with complex congenital heart disease in Guatemala.

In 1953, shortly after relocating to Guatemala, Castañeda met his wife, Arcely Rey-Rosa. They share a European background because Arcely spent World War II in Italy. They were married in 1956 while Castañeda was still a medical student and welcomed their first daughter, Silvana, in 1957. She was quickly followed by her sister Claudia in 1958 and their youngest brother, Aldo Jr, in 1965 when Castañeda was a junior faculty member. None followed in his footsteps with a career in medicine. Castañeda is an 


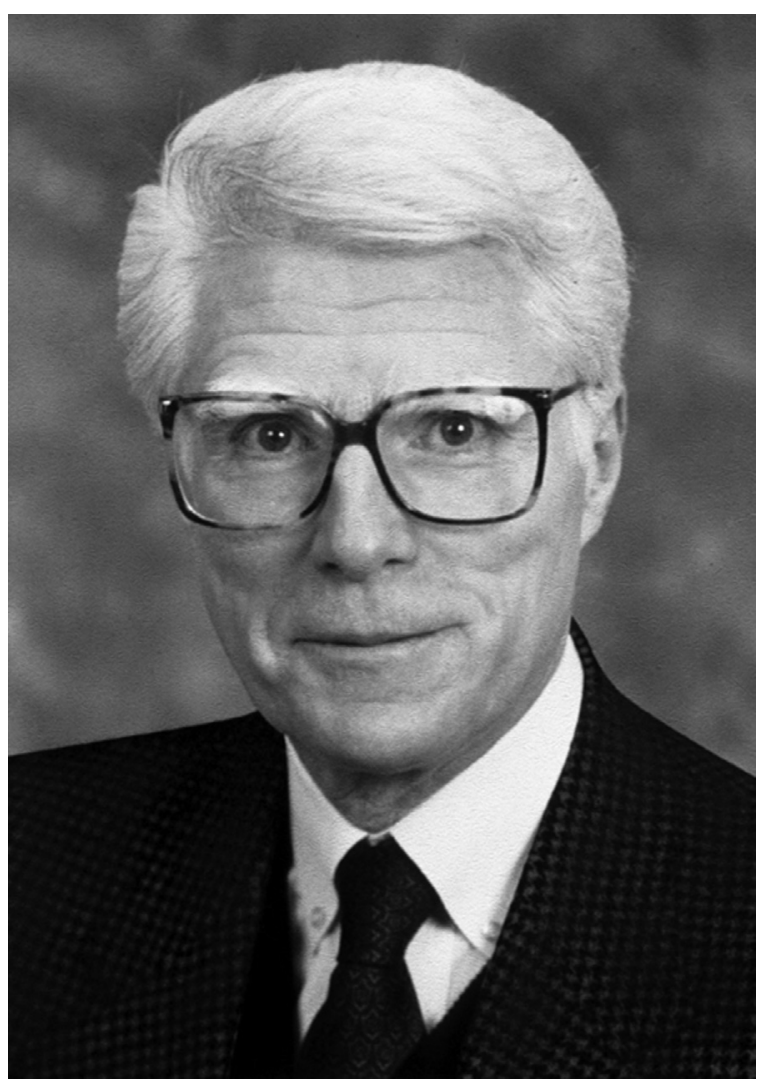

FIGURE 1. Aldo R. Castañeda, MD, PhD, at Boston Children's Hospital, 1990s.

avid reader, historian, and patron of the arts. To this day, he travels to Canada on an annual trek with friends from his early years at Boston Children's Hospital to enjoy Shakespeare at the Stratford Festival.

Castañeda completed his surgical residency at the prestigious University of Minnesota, the birthplace of open heart surgery, and a pioneering and outstanding academic training program. Under the guidance and vision of Owen Wangensteen (chairman of the Department of Surgery), the University of Minnesota was the epicenter of surgical research and innovation. Wangensteen successfully recruited many of the greatest contributors to modern cardiac surgery, including F. John Lewis, who closed the first atrial septal defect in $1952^{3}$; C. Walton Lillehei, who introduced human cross-circulation to cardiopulmonary bypass in 1953 ${ }^{4}$; and Norman Shumway (67th AATS president), who developed the technique of heart transplantation. ${ }^{5}$ This was the place to be for a young physician interested in cardiac surgery. Castañeda was initially accepted for a 1 -year trial period. Within 6 months he was offered an opportunity to remain for his entire residency. He received his doctorate in experimental surgery in 1963, the same year he finished his surgical training. Upon completion of his training he became a faculty member and quickly moved through the academic ranks, achieving full professor status in just 7 years (when he was aged 40 years). During those years he worked closely with Richard Varco, MD, an important contributor (and senior author) on most of the early Minnesota cardiac surgical reports. Ultimately, Castañeda stayed at the University of Minnesota for 14 years as a resident, fellow, and faculty member.

In 1972, at age 42 years, he was recruited to succeed Robert E. Gross (44th AATS president) as chief of the world's preeminent congenital heart surgery program at Boston Children's Hospital (Figure 2). In 1975, he became the William E. Ladd Professor of Child Surgery at Harvard Medical School and in 1981 became surgeon-in-chief at Boston Children's Hospital. He remained in those positions until his retirement in 1995 after spending 23 years changing the way congenital heart surgery is performed around the world and directly influencing and inspiring countless surgeons, including John Mayer (42nd president of the Society of Thoracic Surgeons), Richard Jonas, and Pedro del Nido (86th and 95th AATS president, respectively). He created an environment, a department, and a congenital heart center that inspired and supported others in landmark developments such as William Norwood's pioneering work on hypoplastic left heart syndrome. His interpersonal skills helped in the creation of a programmatic approach to congenital heart disease that has become the model of collaboration for pediatric cardiac surgeons, cardiologists, and nurses the world over.

$\mathrm{He}$ is most known for his introduction of neonatal and early corrective surgery to the world of congenital heart surgery. His early research on cardiopulmonary bypass demonstrated that the influence was similar in puppies weighing $2 \mathrm{~kg}$ as in adult animals. ${ }^{6}$ These early findings inspired him to push for earlier repairs in human beings that were previously thought to be impossible. His advocacy for neonatal corrective surgery has been the most important contribution to congenital heart surgery made in recent decades. The Castañeda Doctrine is this: Operate as soon postnatally as the patient needs it. Whenever possible, do corrective surgery not palliative surgery. One operation is better than 2 (or more).

His focus on neonatal early complete repairs revolutionized the approach to transposition of the great vessels. Until the early 1980s, patients would undergo an initial palliative atrial septectomy and return later for an atrial switch operation that provided a physiologic but not an anatomic repair. With his focus on neonatal surgery and substantial contributions to hypothermic circulatory arrest, Castañeda and Norwood, inspired by Jatene's arterial switch operation in older infants, ${ }^{8}$ successfully performed the arterial switch operation in a series of neonates, forever changing the management and long-term outcome for these patients who now benefit from an anatomic repair. ${ }^{9}$ His focus on patients with transposition of the great vessels has led to a series 


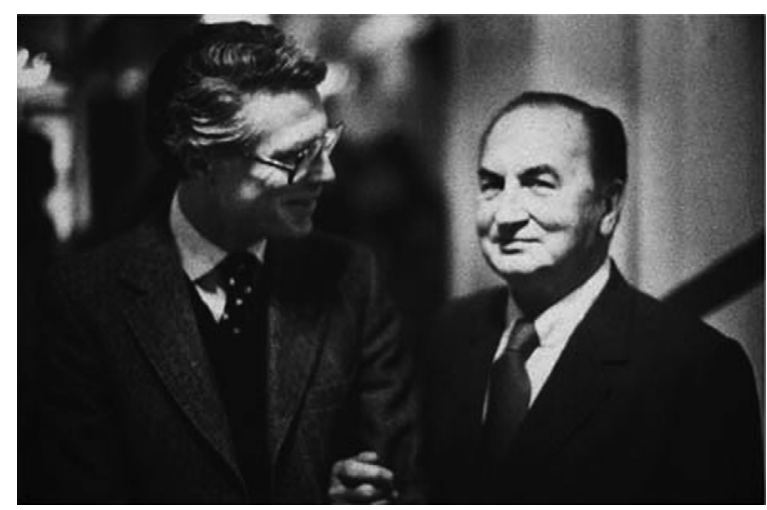

FIGURE 2. Aldo R. Castañeda and Robert E. Gross at Boston Children's Hospital, 1972.

of landmark studies evaluating the neurodevelopmental outcomes of patients undergoing circulatory arrest beginning in $1991 .{ }^{10}$ Always the pioneer, neurodevelopment outcomes are now, 30 years later, the hottest topic in congenital heart disease research.

Upon his retirement from Boston Children's Hospital, Castañeda spent a brief period of time in Switzerland but ultimately chose to return to Guatemala to develop the first and only congenital heart program in Central America. He believed that the only way poor children in Guatemala would be able to receive the care needed would be through the creation of a viable and sustainable local pediatric cardiovascular surgery program. ${ }^{11}$ His 3 main tenets for the program were clinical viability, training of the necessary team, and research. He established the Aldo Castañeda Foundation in 1998 to help provide the necessary financial resources to maintain the program. Initially, Castañeda was the only surgeon and he provided his services pro bono to help save the lives of these children. Since its inception, the program has performed more than 2000 operations and is now the referral center for children with congenital

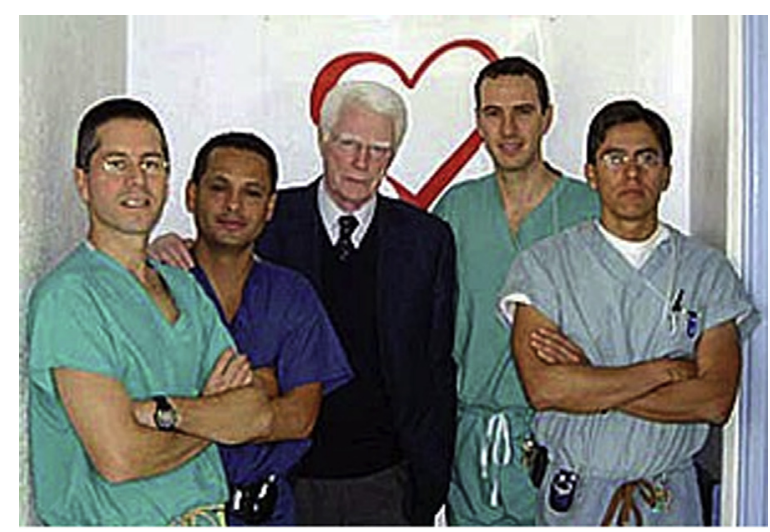

FIGURE 3. The surgical team in Guatemala. From right: Juan LeonWyss, Oscar Veras, Aldo R. Castañeda, Vladimiro L. Vida, and Ivan Vides. heart disease from El Salvador, Honduras, Nicaragua, Belize, the Dominican Republic, and Haiti. ${ }^{12}$ The program is now supported by 3 full-time surgeons who were trained by Castañeda (Figure 3).

We had the opportunity to speak with Castañeda's dear friend Amon Rosenthal, a pediatric cardiologist who first met Castañeda when he arrived at Boston. It was Rosenthal who pushed for Boston Children's Hospital to offer Castañeda the position over another purportedly more qualified candidate. He recalls that he was immediately inspired by Castañeda, who was positive, dedicated, and devoted not just to the care of patients but to the advancement and education in the field of congenital heart disease. These are the exact same qualities that Rosenthal saw in Edward L. Bove (past president of the Congenital Heart Surgeons Society) when he later recruited him to be the head of congenital heart surgery at the University of Michigan.

In recalling his early impressions of Castañeda, Richard van Praagh noted,

He transformed the cardiology and cardiac surgery services. Immediately, he brought us into the modern age. As the cardiac pathologist, I had a front row seat to this change. Gone were the thick black silk sutures of the pre-1972 days. Now we were looking at fine, perfectly placed polyethylene green sutures-an amazing transformation. A legend developed at Children's Hospital of Boston that BC really stood for Before Castañeda. It was not rare for Professor Castañeda to interrupt the presentation and say, 'No, no. I just did a bad operation.' This kind of courageous intellectual honesty then led to a careful consideration, right there in the conference room, on how he could do it better the next time.

John Mayer, MD, recalls that a favorite Castañeda admonition was, "A surgeon that cannot be self-critical is lost." It was this candor and humility that helped to catapult the field forward. One of his first trainees at Boston Children's Hospital described Castañeda as a man with sharp intellect, technical virtuosity, pioneering boldness, dedication to the pursuit of excellence, and a deep appreciation of the human side of medicine and science. ${ }^{1}$ A true Renaissance man, Castañeda, who is fluent in 5 languages, often spoke to visitors on his rounds in their own language. This is a rare occurrence in US hospitals, but helped foster international relationships and collaboration for his program.

In his AATS Presidential Address, Castañeda capitalized on his knowledge and passion for Greek mythology. He opened with:

Apollo, according to mythology, was the god of the intellect, the arts and the healing. The term Apollonian also implies harmony, balance, rationality, loyalty, and discipline—all desirable characteristics 
for cardiothoracic surgeons... Surgery is an eminently moral act, and, by living with human suffering, we learn to appreciate man's moral nature... The privilege to participate in preserving and improving life provides us with our purest professional satisfaction. Often we find well-trained professionals who have mastered scientific facts, statistical proofs, and surgical techniques but who lack more elusive qualities such as respect for the dignity of man, empathy, humility, and interpersonal skills. A meaningful background in the humanities requires schooling in philosophy, history, sociology, literature, and the arts - tonal, visual, and plastic... Humanities offer us a vision that transcends our own fate and, very importantly, teaches us understanding. It also heightens our concern for our patients, not only as carriers of intrathoracic pathology but as beings in need of human contact and compassion. We must never abrogate this unique and mutually rewarding surgeon-patient relationship and responsibility to others. The humanistic preparation must start at home, be continued throughout school, and eventually become part of life. In short, we all must endeavor to regain our Apollonian aura. ${ }^{13}$

Ideals to which thoracic surgeons should aspire, according to Castañeda, are those embodied by Apollo, including harmony, balance, rationality, loyalty, and discipline. In addition, he stated that "an important aesthetic component, juxtaposing art and science, and demanding, in addition, honesty, courage, judgment, vision, erudition, compassion, and a consuming commitment to the pursuit of excellence and high ethical standards" are also needed. ${ }^{13}$ His description of the Apollonian surgeon in actuality was a perfect reflection of the qualities that have made him the leader, genius, and cherished colleague that he is. ${ }^{1}$

Castañeda's spirit and drive have been infused throughout the field of congenital heart surgery. He is most noted for 3 major contributions to the field: neonatal and early corrective surgery for complex congenital heart disease; a programmatic approach to the care of patients with congenital heart disease; and, his legacy, a fully functional and independent congenital heart surgery program in Guatemala. He once stated, "All our actions must be directed, first and foremost, to the relief of human suffering." 13 This is evident through his dedication to the profession, education of trainees, clinical advancements, and passion for building both a world-renowned, high-technology congenital heart surgery program within the booming United States health care system and a viable, self-sustaining, and high-quality congenital heart surgery center in Guatemala.

\section{References}

1. Sade RM. Aldo R. Castañeda: Apollonian surgeon. Ann Thorac Surg. 1995;60: S490-3.

2. Castañeda AR. Nazi medicine during the 3rd Reich. Honorary lecture. CHSS/ ECHSA Second Joint Meeting, Warsaw, Poland, September 11, 2008.

3. Lewis FJ, Taufic M. Closure of atrial septal defects with the aid of hypothermia: experimental accomplishments and the report of one successful case. Surgery. 1953;33:52-9.

4. Lillehei CW, Cohen M, Warden HE, Varco RL. The direct-vision intracardiac correction of congenital anomalies by controlled cross circulation: results of thirty-two patients with ventricular septal defects, tetralogy of Fallot, and atrioventricularis communis defects. Surgery. 1955;38:11-29.

5. Lower RR, Stofer RC, Shumway NE. Homovital transplantation of the heart. J Thorac Cardiovasc Surg. 1961;41:196-204.

6. Visduh-Arom K, Miller ID, Castañeda AR. Hematological studies following total cardiopulmonary bypass in infant puppies. Trans Am Soc Artif Intern Organs. $1969 ; 15: 161-4$

7. Van Praagh R. Aldo Ricardo Castañeda, MD, PhD: what is he really like? Thorac Cardiovasc Surg. 2010;58:318-9.

8. Jatene AD, Fontes VF, Paulista PP, Souza LC, Neger F, Galantier M, et al. Anatomic correction of transposition of the great vessels. J Thorac Cardiovasc Surg. 1976;72:364-70.

9. Castañeda AR, Norwood WI, Jonas RA, Colon SD, Sanders SP, Lang P. Transposition of the great arteries and intact ventricular septum: anatomical repair in the neonate. Ann Thorac Surg. 1984;38:438-42.

10. Bellinger DC, Wernovsky G, Rappaport LA, Mayer JE Jr, Castañeda AR, Farrell DM, et al. Cognitive development of children following early repair of transposition of the great arteries using deep hypothermic circulatory arrest. Pediatrics. 1991;87:701-7.

11. Castañeda AR. Final thoughts. World J Pediatr Congenit Heart Surg. 2011;2: $115-8$.

12. Vida VL, Sade RM, Stellin G, Aldo R. Castañeda. Cardiol Young. 2006;16:221-8. 13. Castañeda AR. The making of a cardiothoracic surgeon: an Appolonian quest. J Thorac Cardiovasc Surg. 2004;108:806-12. 